\title{
Structural-functional Model of Investment Resources Formation of Fixed Assets Reproduction
}

\author{
Boyko Andrei Anatolievich \\ (a) Dept. of Management \\ Siberian Federal University, \\ (b) Dept. of Management \\ Reshetnev Siberian State University of Science and \\ Technology \\ Krasnoyarsk, Russia
}

\section{Tynchenko Vadim Sergeevich}

(a) Dept. of Production Machinery and Equipment for

Petroleum and Natural Gas Engineering

Siberian Federal University,

(b) Dept. of Information Control Systems

Reshetnev Siberian State University of Science and

Technology

Krasnoyarsk, Russia

\author{
Kukartsev Vladislav Viktorovich \\ (a) Dept. of Informatics \\ Siberian Federal University, \\ (b) Dept. of Information Economic Systems \\ Reshetnev Siberian State University of Science and \\ Technology \\ Krasnoyarsk, Russia
}

\author{
Nasyrov Ilnar Rafinatovich \\ Military Training Center \\ Reshetnev Siberian State University of Science and \\ Technology \\ Krasnoyarsk, Russia
}

\author{
Kukartsev Viktor Alekseevich \\ Dept. of Material Science and Technology of Metal Processing \\ Siberian Federal University \\ Krasnoyarsk, Russia
}

\begin{abstract}
The main problem faced by the company in the implementation of the process of reproduction of fixed assets is a problem of formation of investment resources. Formation of investment resources is quite a complex process, which turns into many problems. The main issues are: diversity of the structure of own capital; growth of the prices of the individual sources of investment resources as increasing their volume; the variety of ways of calculating weights of individual sources (the problem of weighting); different approaches to the determination of the actual magnitude of resource investment at market and at cost; the necessity of accounting rates of depreciation; choice of optimization method of structure of sources of investment resources. The article describes the process of formation of investment resources. The purpose of the description is to build a structural-functional model of the process in the abstract IDEF0 to build an automated system to manage this process. The model of the formation of investment resources consists of two structural-functional diagrams. The first one (the root) shows the inputs and outputs that control the effects and mechanisms of implementation of the process. The second one shows the decomposition for the root of the graph.
\end{abstract}

Keywords-formation of investment resources, structuralfunctional model

\section{INTRODUCTION}

Engineering capabilities and cost efficiency of operation and development of machinery and equipment production are defined by the engineering capacity and level of use of the active part of its fixed capital assets [1]. The 1990s faced the qualitative change of fixed capital assets renewal. For the contemporary economy, the aging process of fixed capital assets (especially its active part) is determined by the impossibly low tempo of new machinery introduction as well as the old machinery retirement. As a result, depreciation of the fixed capital assets in machinery has reached its critical level [2,3]. One of the main reasons restricting the tempo of fixed capital assets production is the lack of investment funds both for the manufacturing sector as a whole and machinery and equipment production in particular [4]. The lack of investment resources as well as the change of terms for their attraction impose new requirements on management of the enterprise investment activity on machinery and equipment production, first of all, on information technologies for management of investment funds generation for enterprise fixed capital assets renewal which are capable to provide the 
rise of effectiveness for investment decisions and hence the rise of tempo for fixed capital assets renewal [5, 6]. At first, it refers to development and use of automated management systems (AMS) for the process that allow to solve the following issues: to choose the option and form of the fixed capital assets renewal, to define the necessity of investment funds for its implementation, to choose the resources of investment funds and its structural optimization [7, 8]. Creation of contemporary information systems is a challenging task which requires the introduction of special methods and instruments. At the initial stage of the information system creation, it is necessary to understand the operating principle of the actual system which is aimed to be automated [9].

To describe the system operation, it is necessary to develop a business process model which is applicable to the investigated sphere. There are standardized methods used for many years and instruments for business process modeling. The best known and widespread of all is the methodology of ICAM Definition Methods (IDEF0) used for structural and functional analysis [10, 11].

Currently, the enterprises of an aerospace sector are constantly facing the problem of low engineering capacity and underuse of their fixed capital assets while developing the innovative projects. For this reason, the subject on the description of investment funds, the generation process introduced in the article is of current interest for them.

\section{THE STRUCTURAL AND FUNCTIONAL MODEL OF INVESTMENT FUNDS GENERATION}

The process of managing the formation of investment resources of reproduction of AMS is influenced by various factors that determine the nature, essential features, causes and conditions of its development. The actions of these factors are manifested via the cause-effect relationships of the processes and phenomena occurring during the formation of investment resources.

Without taking into account both the qualitative and quantitative impact of these factors, it is impossible to make informed management decisions on the formation of investment resources for the reproduction of AMS.

These characteristics of the influence of factors can be identified through qualitative and quantitative changes of certain technical and economic (factorial) indicators. Therefore, it is necessary to identify and systematize these factors.

Based on the business process modeling standard IDEF0 [12] and AllFusion Process Modeler (BPwin) software, the structural and functional model of investment funds generation process for the enterprise fixed assets renewal has been developed. This model is described below.

The modeling process of any system in IDEF0 begins with the context determination, or in other words, the hypothetical level of system description. The context includes the definition of the modeling objectives and the perspective of the model [13].
The scope of research in this work is limited to the investment funds generation process for the enterprise fixed assets renewal. At the input of the process, we have the volume of the necessary investment funds for the planned periods of time. At the output of it, we should obtain the optimal structure of investment funds. The objective of the modeling is to develop a structural and functional model of the investment funds generation process to elaborate an information system for this process management. The description of the investment funds generation process is considered from the point of view of the Investment Manager, who makes decisions concerning the process. After defining the context, we proceed directly to the model developing.

The model as per the IDEF0 notation represents a set of hierarchically organized and interrelated diagrams. The top of the tree structure of the diagrams belongs to the context diagram which introduces the general description of the system and its interrelation with the external environment. Figure 1 shows the context diagram of the investment funds generation process. The input parameters of the process are the volume of the necessary investment funds, the chart of investment funds delivery as per the planned periods of time, the resources of investment funds - monetary assets (amortization, income, credit, and others) and fixed assets (lease etc.) [14, 15]. As a result of the input resources transformation, the following parameters are gained at the output: the optimal structure of investment funds which provides the minimum value of the weighted average cost of capital. The input parameters transformation is influenced by the following control values: type of legal entity, the model for calculating the investment funds, internal rates of return and methods for determination of investment funds structure. The process operation depends on the person authorized to make decisions (the Investment Manager). Having described the system as a whole, it is divided into large parts. This process is called the functional decomposition. The diagrams depicting each part and their interrelation are called the decomposition diagrams [16].

\section{RESULTS AND DISCUSSION}

Figure 2 shows the context diagram decomposition described above. The context diagram is reduced to four business processes: determination of available resources of investment funds, calculation of investment funds cost, calculation of the weighted average cost of investment funds and calculation of investment potential. The diagram shows the business processes in order of their prevalence. The business process shown in the upper left corner shall be performed first. The processes on the right shall be performed later from the top to the bottom of the page. In the decomposition diagram, business processes are numbered according to run time. 


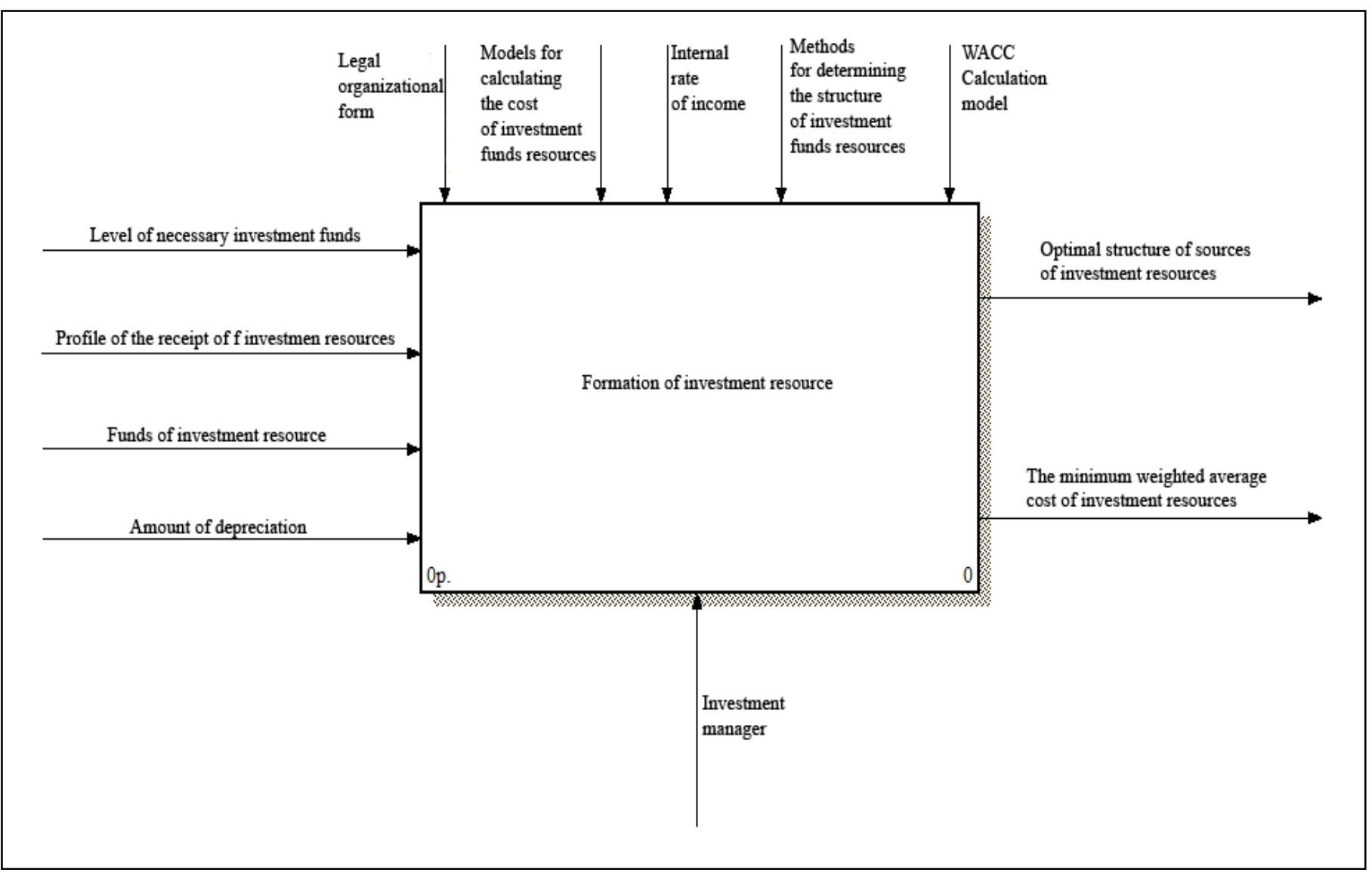

Fig. 1. Context diagram of investment resources formation

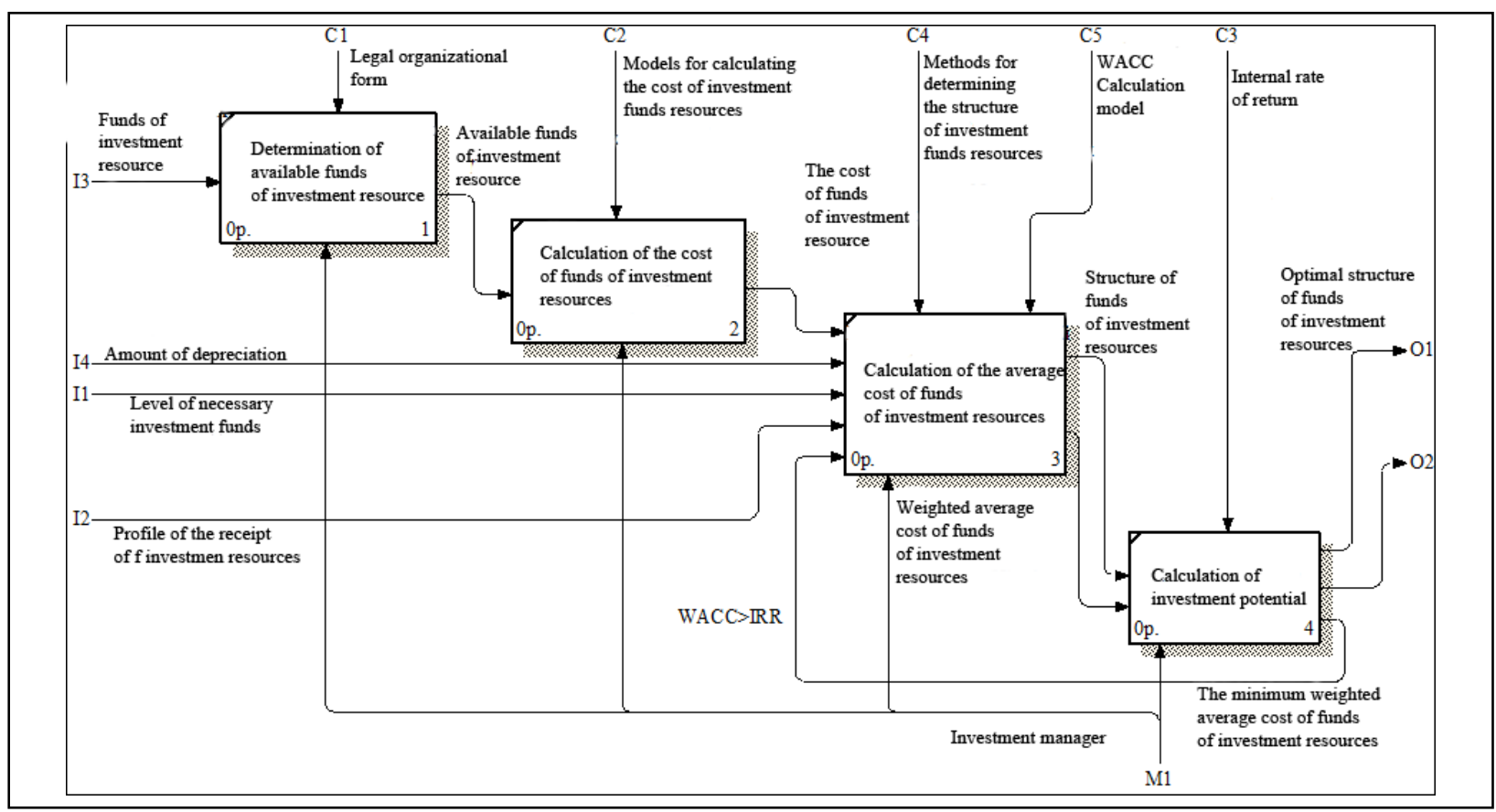

Fig. 2. Decomposition of the context diagram of the formation of investment resources 
The input parameter of the business process for determination of available resources of investment funds is the parameter called the list of investment funds. Depending on the type of legal entity (unitary enterprises, joint stock companies etc.), the list of available investment funds is specified (the output parameter).

\section{CONCLUSION}

This article describes the structural and functional model of investment funds generation for enterprise fixed capital assets renewal. It also demonstrates the context diagram of the process and its decomposition to subprocesses. The curves of interface connections of inputs, outputs, correcting conditions and mechanisms of process operation are described as well.

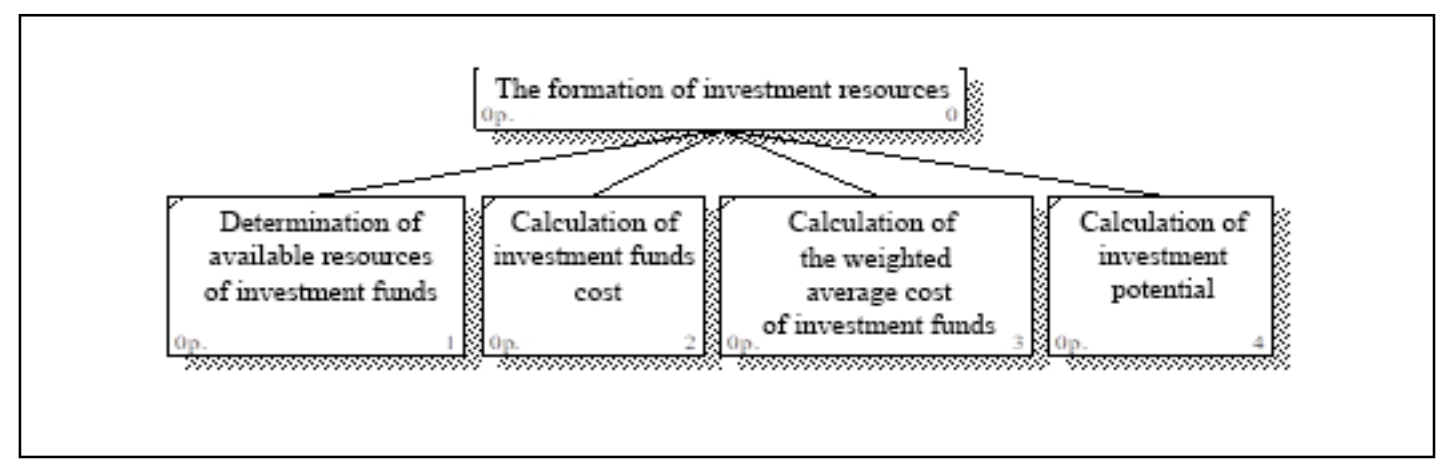

Fig. 3. A structural-functional model of the process of formation of investment resources

The following business process is the calculation of investment fund cost. The input parameter for this process is the list of available investment funds. Based on the parameter of value assessment, the output parameter of each of the investment fund is calculated.

The third business process is the calculation of the weighted average cost of investment funds. The input parameter for this business process is the cost of available investment funds. The result of this business process together with the given parameters determining the structure of investment funds and the model used for calculation of the weighted average cost of investment funds (WACC) is the output parameters for the structure of investment funds and their weighted average cost.

The final business process is the calculation of investment potential of the project. This business process compares the internal rate of return (IRR) of the project including the weighted average cost of investment funds. If the internal rate of return is lower than the weighted average cost of the investment funds, we shall come back to the third business process and recalculate the structure and weighted average cost of investment funds. This process is repeated until the opposite result is obtained. If the internal rate of return is greater than or equals the weighted average cost, the calculation is complete, so at the output, the desired optimal structure of the investment funds and the minimum value of the weighted average cost of investment funds are obtained.

The process of creating a structural-functional model is interactive. That is why business processes can change their hierarchical location. In order not to get confused, a special diagram of the node tree (figure 3 ) is constructed during the decomposition of the model.
Thus, the demonstrated diagrams provide system vision of investment funds generation process and furthermore, these diagrams can be applicable to elaborate the AMS for this process.

\section{References}

[1] M.A. Stolyarova, O.L. Shulgaty, M.R. Dzagoeva, L.I. Bestaeva, V.A. Kaitmazov, Generalization of foreign experience in the reproduction and recording of fixed assets, International Journal of Applied Business and Economic Research, pp. 241-250

[2] A.V. Kukartsev, K.I. Gorlevskiya, Principles of management of innovative business processes of the enterprise of the space-rocket industry, Economy and management of control systems, v.1, № 1 (11), p. 044-052, 2014.

[3] Oliynyk, I.V. Fixed assets management in the frameworks of classical and contemporary theories, Actual Problems of Economics, №168 (6) статья № A047, pp. 47-53, 2015.

[4] A.V. Kukartsev, K.I. Gorlevskiya, I.V. Ogurchenok, Management of innovative activity of the enterprise of the space-rocket industry on the basis of process approach, Economy and management of control systems, v. 11. № 1.3, p. 358-367, 2014.

[5] K.I. Gorlevskiya, I.V. Ogurchenok, A.V. Kukartsev, Scientific approaches to management of business processes of the enterprise of the space-rocket industry, Current problems of aircraft and astronautics, v.2. № 10, p.113-114, 2014

[6] A. A. Boyko, V.V. Kukartsev, K. Y. Lobkov, A.A. Stupina, " Strategic planning toolset for reproduction of machine-building engines and equipment ", J. Phys.: Conf. Ser.

[7] A.A. Stupina, A.A. Shigina, A.O. Shigin, M.V. Karaseva, and S.N Ezhemanskaja, Automated intellectual system with the short-duration nature of feedback Life Science, no. 11, pp. 302-306, 2014.

[8] K.I. Gorlevskiya, A.V. Kukartsev, Regulation of innovative business processes of the enterprise of the space-rocket industry, Bulletin of the Siberian state space university of the academician M.F. Reshetnev, № 1 (53), pp. 194-198, 2014.

[9] J.L. Gissel, A case of fixed asset accounting: Initial and subsequent measurement, Journal of Accounting Education, №37, pp. 61-66, 2016.

[10] Y. Vertakova, S. Klevtsov, M. Klevtsova, Technology of fixed assets assessment in investigating the stability of the industrial complex of the region, Proceedings of the 26th International Business Information 
Management Association Conference - Innovation Management and Sustainable Economic Competitive Advantage: From Regional Development to Global Growth, IBIMA 2015, pp. 3230-3236, 2015.

[11] L. Ye, Research on enterprise fixed assets management based on KMEANS clustering algorithm, Agro Food Industry Hi-Tech, №28 (3), pp. 2540-2544, 2017.

[12] K.I. Gorlevskiya, I.V. Ogurchenok, A.V. Kukartsev, Control algorithm of innovative business processes of the enterprise of the space-rocket industry, Bulletin of the Siberian state space university of the academician M.F. Reshetnev, № 2 (54), p. 158-164, 2014.

[13] H.M. Nijam, Motives for Reporting Fixed Assets at Revalued Amount: Evidence from a Developing Economy, Global Business Review, №19 (3), pp. 604-622, 2018.
[14] G.S. Klychova, A.R. Zakirova, K.Z. Mukhamedzyanov, E.R. Sadrieva, A.S. Klychova, Development of audit system for operations with fixed assets as a tool for efficiency improvement of social activity of the enterprise, Journal of Engineering and Applied Sciences, №12 (19), pp. 4966-4973, 2017.

[15] A.V. Kukartsev, K.I. Gorlevskiya, Instruments of management of business processes of the enterprise of the space-rocket industry in the competitive environment, the Modern competition, № 5 (41), pp. 081091, 2013.

[16] M.D. Mattei, N. Mattei, Analysis of fixed and biased asset allocation rebalancing strategies, Managerial Finance, №42 (1), pp. 42-50, 2016. 